\title{
Effect of Long Term Prediagnostic Aspirin Intake on the Prognosis of Esophageal Squamous Cell Carcinoma Receiving Radical Surgery
}

\section{Wenqiao Jia}

Shandong University Qilu Hospital https://orcid.org/0000-0002-4510-1409

\section{Cong Wang}

Shandong University Qilu Hospital

\section{Ming Lu}

Shandong University Qilu Hospital

Yufeng Cheng ( $\nabla$ chengyufeng_2016@163.com )

Shandong University Qilu Hospital

\section{Research Article}

Keywords: esophageal squamous cell carcinoma, aspirin, prognosis

Posted Date: May 4th, 2021

DOI: https://doi.org/10.21203/rs.3.rs-446568/v1

License: (c) (i) This work is licensed under a Creative Commons Attribution 4.0 International License. Read Full License 


\section{Abstract}

\section{Background:}

The effect of long term prediagnostic aspirin intake on the prognosis of esophageal squamous cell carcinoma (ESCC) is unclear. We aimed to reveal the effect of long term prediagnostic aspirin intake on survival of ESCC patients receiving radical surgery.

\section{Methods:}

147 eligible ESCC patients who received radical surgery for primary treatment were enrolled in this study. Patients who had used aspirin regularly for more than 3 months before diagnose were classified as aspirin group and patients who had never used aspirin before diagnose and surgery were served as nonaspirin group. The recurrence rate, disease-free survival (DFS) and overall survival (OS) were compared between the two groups to verify the effect of aspirin.

\section{Results:}

Patients were clarified into aspirin group $(n=57)$ and non-aspirin group $(n=90)$. The DFS and OS were both significantly shorter in aspirin group than non-aspirin group (DFS: $23.1 \pm 18.0$ months vs. $30.9 \pm 19.8$ months, $\mathrm{P}=0.018$; OS: $29.8 \pm 17.4$ months vs. $35.2 \pm 18.2$ months, $\mathrm{P}=0.082$ ). Survival analysis revealed that OS decreased in aspirin group than in non-aspirin group, however, it did not reach significance $(P=0.074)$. DFS decreased significantly in aspirin group than non-aspirin group in both univariate $(P=0.007)$ and multivariate $(P=0.002)$ survival analysis. Subgroup analysis revealed that in pTNM stage 2, OS and DFS were reduced in non-aspirin group compared with aspirin group $(P=0.048$ and $P=0.003$, respectively), while no difference was found in stage 3 .

\section{Conclusions:}

Long term prediagnostic aspirin intake may cause poor DFS in ESCC patients receiving radical surgery, especially for those in pTNM stage 2 .

\section{Background}

Esophageal cancer is a major health problem all over the world. The estimated new cases and deaths of esophageal cancer are 572,034 and 508,585 respectively in the worldwide in 2018 [1]. Esophageal cancer is the top 10 most frequently cause of cancer death in both male and female [1]. In China, esophageal cancer turned out to be the top 10 most commonly diagnosed cancer in both men and women (3rd in men and 6th in women) [2]. Esophageal squamous cell carcinoma (ESCC) is the major type and accounts for more than $90 \%$ of esophageal cancer in China [3]. The effective preventive methods and prognostic indicators are very necessary for ESCC. 
Aspirin is an analgesic and antipyretic agent which is widely used. Studies have indicated aspirin may reduce the incidence and mortality of certain cancers $[4,5]$. It was observed that the anti-tumor mechanisms of aspirin include COX dependent and COX independent pathways through inhibition of angiogenesis [6], induction of autophagy and apoptosis [6-9], anti-proliferative activity [10], and inhibition of metastasis [11-13]. U.S. Preventive Services Task Force has recommended aspirin as a primary preventive agent of cardiovascular disease and colorectal cancer in adults in 2016 [14]. However, increasing studies indicated the possible risk of clinical aspirin use which make the role of aspirin uncertain. A study including 6694 endometrial cancer patients with a maximum follow-up of 13 years did not found indication that pre- or post-diagnostic low-dose aspirin use reduced mortality for endometrial cancer [15]. Previous studies suggest that aspirin may reduce prostate cancer risk, while recent studies found aspirin was not associate with reduced prostate cancer risk [16, 17]. A large Asian cohort study did not find impact of aspirin on pancreatic cancer development [18]. Besides, there was no evidence that low-dose aspirin use before or after diagnosis was associated with a reduced risk of adverse outcomes overall in breast cancer $[19,20]$.

It was reported aspirin could be used in esophageal cancer patients as an adjuvant chemotherapy following the standard surgery [21, 22]. However, two large cohort studies in England contained 4654 esophageal cancer patients and 3833 gastric cancer patients showed that the cancer mortality proportions of participants surviving 1 year were similar in aspirin users versus non-users after diagnosis with cancer [23]. Another cohort of esophageal cancer patients indicated pre-diagnosis aspirin use was not associated with all-cause or cancer-specific mortality but could increase the risk of interval metastatic disease [24]. Considering the conflicting results of aspirin on esophageal cancer, this study aimed to investigate the effect of long term pre-diagnostic aspirin intake on the prognosis of ESCC.

\section{Methods}

\section{Patients}

We collected all newly diagnosed ESCC patients who received potential radical surgery for primary treatment in Qilu Hospital of Shandong University from 1 January 2010 to 31 December 2014. We selected all the patients who had regularly used aspirin for a long-term ( $\geq 3$ months) before diagnose and surgery as the aspirin group and randomly chose another 90 ESCC patients who had never used aspirin or other COX-2 selective NSAIDs before diagnose and surgery as the control group. The reasons of aspirin intake were treatments for cardiovascular and cerebrovascular diseases, which were not the death reasons for the aspirin group. The American Joint Committee on Cancer TNM staging system was used in this study [25]. Undergoing radiotherapy and/or chemotherapy or not after the operation is not an exclusion criterion in this study. The exclusion criteria: lost to follow up, coexistence of other malignancies, resection not for curative intent, stage 0 disease, distant metastasis, non-cancer death. Ultimately, 147 patients were included in this study (57 in aspirin group, 90 in control group). The characteristics of patient, tumor, treatment and the final outcome were retrieved from the Medical Records Room or by phone call follow-up. During the first 2 years after surgery, follow-up visits were performed 
every 3 months. After that follow-up visits were performed every 6 months up to death or the end of the study (29 November 2016).

\section{Study design}

A hospital-based retrospective cohort study was performed. Patient-related characteristics (age, gender, smoking, drinking, prediagnostic aspirin intake) and tumor-related characteristics (tumor location, tumor length, differentiation grade, pathological tumor-node-metastasis (pTNM) classification, treatment method) were investigated. We used disease-free survival (DFS) and over-all survival (OS) to evaluate the prognosis. The definition of DFS in this paper was the period of time from the radical operation to the identifiable time for first relapse or death or last follow-up, whichever firstly occurred. OS was from the radical operation date to the death date from tumor cause or last follow-up.

\section{Statistical analysis}

In data analysis of patient-related characteristics and tumor-related characteristics, Chi-square test and student's t-test were applied for categorical variables and continuous variables, respectively. Survival curves were constructed with the Kaplan Meier method to estimate the distribution of the DFS time and OS time in the two different groups. Cox proportional hazards modeling was used to investigate multiple risk factors that have been shown to influence ESCC prognosis [95\% confidence intervals (Cls)]. P values less than 0.05 were considered to be statistically significant. SPSS version 21.0 (SPSS Inc., Chicago, IL, USA) was used for all statistical analyses.

\section{Results}

\section{Patients' characteristics}

147 patients were recruited in this study, including 123 men and 24 women (49 males and 8 females in aspirin group, 74 males and 16 females in non-aspirin group, $P=0.550$ ). Twenty patients were less than 65 years old and 37 patients were over 65 years old in aspirin group, while 47 less than 65 years old and 43 over 65 years old in non-aspirin group $(P=0.042)$. All other patient-related characteristics of aspirin group and non-aspirin group were not significantly different (all $P>0.05)$. Patients' characteristics are shown in Table 1. 
Table 1

Tumor-related characteristics in aspirin and non-aspirin groups

\begin{tabular}{|c|c|c|c|}
\hline Characteristics & $\begin{array}{l}\text { Aspirin group } \\
(n=57)\end{array}$ & $\begin{array}{l}\text { Non-aspirin group } \\
(n=90)\end{array}$ & $P$ value \\
\hline Age & & & 0.042 \\
\hline$\leq 65$ & 20 & 47 & \\
\hline$>65$ & 37 & 43 & \\
\hline Gender & & & 0.550 \\
\hline Male & 49 & 74 & \\
\hline Female & 8 & 16 & \\
\hline Smoker & & & 0.181 \\
\hline Yes & 38 & 50 & \\
\hline No & 19 & 40 & \\
\hline Drinker & & & 0.362 \\
\hline Yes & 36 & 50 & \\
\hline No & 21 & 40 & \\
\hline Tumor location & & & 0.918 \\
\hline Neck & 1 & 2 & \\
\hline Upper & 4 & 4 & \\
\hline Middle & 34 & 56 & \\
\hline Lower & 18 & 28 & \\
\hline Tumor length & & & 0.535 \\
\hline$\leq 4 \mathrm{~cm}$ & 23 & 41 & \\
\hline$>4 \mathrm{~cm}$ & 34 & 49 & \\
\hline Differentiation grade & & & 0.692 \\
\hline Well & 12 & 14 & \\
\hline Moderate & 25 & 43 & \\
\hline Poor & 20 & 33 & \\
\hline pTNM stage & & & 0.942 \\
\hline I & 4 & 5 & \\
\hline
\end{tabular}




\begin{tabular}{|llll|}
\hline Characteristics & $\begin{array}{l}\text { Aspirin group } \\
(\mathbf{n = 5 7 )}\end{array}$ & $\begin{array}{l}\text { Non-aspirin group } \\
(\mathbf{n}=\mathbf{9 0})\end{array}$ & P value \\
\hline II & 31 & 46 & \\
\hline III & 21 & 37 & \\
\hline IV & 1 & 2 & 0.750 \\
\hline Treatment & & & \\
\hline Surgery & 24 & 40 & \\
\hline Surgery + Radiotherapy, & 6 & 5 & \\
\hline Surgery + Chemotherapy & 7 & 11 & \\
\hline Surgery + Radiotherapy+ Chemotherapy & 20 & 33 & \\
\hline
\end{tabular}

\section{Prognostic difference between aspirin group and non- aspirin group}

The recurrence rate and tumor-specific mortality rate of aspirin group were both higher than non-aspirin group (recurrence rate: $70.2 \%$ vs. $48.9 \%, P=0.011$ and mortality: $56.1 \%$ vs. $43.3 \%, P=0.130$ ). The DFS and OS were both significantly shorter in aspirin group than non-aspirin group (DFS: $23.1 \pm 18.0$ months vs. $30.9 \pm 19.8$ months, $P=0.018$ and OS: $29.8 \pm 17.4$ months vs. $35.2 \pm 18.2$ months, $P=0.082$ ).

\section{Univariate and multivariate survival analysis results}

In the univariate survival analysis, we used Kaplan-Meier curves to identify the effect of long term prediagnostic aspirin intake on OS and DFS. OS decreased in aspirin group than in non-aspirin group, however, it did not reach significance $(P=0.074)$. DFS decreased significantly in aspirin group than in non-aspirin group $(P=0.007)$. Significant factors of univariate survival analysis were included in the Cox proportional hazards model (Table 2). The results showed that only PTNM stage was significant predictor for OS (2.496(1.742-3.575); $P<0.001)$. For DFS prediction, aspirin intake (HR, 0.502(0.325-0.777); $P=$ 0.002 ) was significant. Besides, tumor location, differentiation grade, pTNM stage and treatment methods were significant as prediction biomarkers. Subgroup analysis of aspirin intake were further conducted according to PTNM stage. In PTNM stage 2, OS and DFS were reduced in non-aspirin group compared with aspirin group $(P=0.048$ and $P=0.003$, respectively), while no difference was found in stage $3(P=0.315$ and $P=0.387$, respectively). Subgroup analysis were not conducted in stage 1 and 4 for the patient number was less than 10 (Fig. 1). 
Table 2

Univariate and multivariate analysis of factors related with DFS and OS of ESCC

\begin{tabular}{|c|c|c|c|c|c|c|}
\hline & \multicolumn{3}{|l|}{ os } & \multicolumn{3}{|l|}{ DFS } \\
\hline & \multirow{2}{*}{$\begin{array}{l}\text { Univariate } \\
\text { analysis } \\
\text { Log-rank P }\end{array}$} & \multicolumn{2}{|c|}{ Multivariate analysis } & \multirow{2}{*}{ 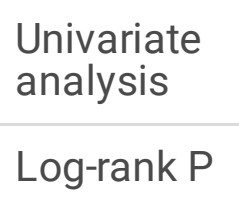 } & \multicolumn{2}{|c|}{ Multivariate analysis } \\
\hline & & $\mathrm{HR}(95 \% \mathrm{Cl})$ & $P$ & & $\mathrm{HR}(95 \% \mathrm{Cl})$ & $P$ \\
\hline Age & 0.762 & - & - & 0.416 & - & - \\
\hline Gender & 0.444 & - & - & 0.611 & - & - \\
\hline Smoker & 0.789 & - & - & 0.858 & - & - \\
\hline Drinker & 0.739 & - & - & 0.485 & - & - \\
\hline $\begin{array}{l}\text { Tumor } \\
\text { location }\end{array}$ & 0.005 & $\begin{array}{l}0.834(0.578- \\
1.205)\end{array}$ & 0.334 & 0.002 & $\begin{array}{l}0.771(0.545- \\
1.088)\end{array}$ & 0.139 \\
\hline Tumor length & 0.985 & - & - & 0.206 & - & - \\
\hline $\begin{array}{l}\text { Differentiation } \\
\text { grade }\end{array}$ & 0.063 & - & - & 0.035 & $\begin{array}{l}1.346(0.985- \\
1.839)\end{array}$ & 0.062 \\
\hline pTNM stage & $<0.001$ & $\begin{array}{l}2.496(1.742- \\
3.575)\end{array}$ & $<.001$ & $<0.001$ & $\begin{array}{l}2.014(1.417- \\
2.861)\end{array}$ & $<.001$ \\
\hline Treatment & 0.078 & & & 0.008 & $\begin{array}{l}1.004(1.000- \\
1.0007)\end{array}$ & 0.054 \\
\hline $\begin{array}{l}\text { Aspirin use or } \\
\text { not }\end{array}$ & 0.074 & - & - & 0.007 & $\begin{array}{l}0.502(0.325- \\
0.777)\end{array}$ & 0.002 \\
\hline
\end{tabular}

\section{Discussion}

Published evidence showed that aspirin may have protective effects for several kinds of cancers, such as lung cancer, prostate cancer, breast cancer, colon cancer, pancreatic cancer, esophageal cancer [26]. Especially in colorectal cancer, aspirin has been approved as a primary preventive agent in adults by U.S. Preventive Services Task Force in 2016 [14]. Contrary to our expected result, we observed that long term prediagnostic aspirin intake may cause poor outcome of ESCC patients who received radical surgery for the first treatment. The recurrence rate and tumor- specific mortality rate of aspirin group were both higher than non-aspirin group. The DFS and OS were both significantly shorter in aspirin group than non-aspirin group. It was observed that DFS of ESCC decreased significantly in aspirin group than non-aspirin group in both univariate and multivariate survival analysis. Long term prediagnostic aspirin intake decreased OS in univariate survival analysis while it was not significant. Subgroup analysis revealed that in pTNM stage 2, OS and DFS were significantly reduced in non-aspirin group compared with aspirin group, while 
no difference was found in stage 3 group. Previous studies conclusions were not consistent on the role of aspirin in esophageal cancer. The current points of aspirin effect on tumor were different. Some studies suggested to use aspirin as an adjuvant chemotherapy following the standard surgery [21, 22], while other studies did not reveal the positive role of aspirin use [23]. Another cohort of esophageal cancer patients indicated pre-diagnosis aspirin use could increase the risk of interval metastatic disease. Multicenter prospective studies are necessary to reveal the role of aspirin plays in tumor.

Previous studies tried to investigate the potential mechanism of aspirin in cancer. It was observed that the anti-tumor mechanisms of aspirin include COX dependent and COX independent pathways through inhibition of angiogenesis [6], induction of autophagy and apoptosis [6-9], anti-proliferative activity [10], and inhibition of metastasis [11-13]. It was reported that post-diagnosis aspirin therapy improved overall survival of colorectal cancer patients, especially for patients with positive PTGS2 (COX-2) expression and mutated PIK3CA tumors[27]. Besides, aspirin suppresses growth in PI3K-Mutant breast cancer by activating AMPK and inhibiting mTORC1 signaling[28]. One study revealed the cytotoxicity and synergistic potential of aspirin and aspirin analogues towards esophageal and colorectal cancer[29]. However, we did not find the clinical positive role of aspirin in esophageal cancer. In vivo and in vitro experiments are necessary to reveal mechanisms of aspirin in esophageal cancer.

The current work has several limitations. Firstly, the work was a retrospective cohort study; some of the results were based on the phone-call follow-up, which may influence the accuracy. Secondly, the sample size was small which may bring bias on the results. We called on large sample, prospective, randomized controlled studies on this field. Thirdly, due to the small sample size, we did not carry out a subgroup analysis according to the dose and frequency of aspirin intake.

\section{Conclusions}

In conclusion, our work found long term prediagnostic aspirin intake caused poor outcome of ESCC and reminded that aspirin cannot benefit all cancer patients.

\section{List Of Abbreviations}

esophageal squamous cell carcinoma (ESCC)

disease-free survival (DFS)

overall survival (OS)

confidence intervals (Cls)

\section{Declarations}

Competing interests: The authors declare that they have no competing interests. 
Authors' contributions: Wenqiao Jia and Cong Wang developed the concept and design of the article. Ming Lu and Yufeng Cheng contributed to the drafting of the manuscript. All authors read and approved the final manuscript.

Funding: No funding.

Ethics approval and consent to participate: This study was approved by the Ethics Committees of Qilu Hospital, Cheeloo College of Medicine, Shandong University.

Consent for publication: Not applicable.

Availability of data and materials: Data and materials are available. Please email chengyufeng_2016@163.com if they are needed.

Acknowledgements: None.

\section{References}

1. Erratum: Global cancer statistics 2018: GLOBOCAN estimates of incidence and mortality worldwide for 36 cancers in 185 countries. CA Cancer J Clin. 2020;70(4):313. Epub 2020/08/09. doi: 10.3322/caac.21609. PubMed PMID: 32767693.

2. Chen W, Zheng R, Baade PD, Zhang S, Zeng H, Bray F, et al. Cancer statistics in China, 2015. CA Cancer J Clin. 2016;66(2):115-32. doi: 10.3322/caac.21338. PubMed PMID: 26808342.

3. Mao YS, He J, Cheng GY. [Current status of surgical management of esophageal cancer in China and the future strategy]. Zhonghua zhong liu za zhi [Chinese journal of oncology]. 2010;32(6):401-4. PubMed PMID: 20819477.

4. Thun MJ, Jacobs EJ, Patrono C. The role of aspirin in cancer prevention. Nature reviews Clinical oncology. 2012;9(5):259-67. doi: 10.1038/nrclinonc.2011.199. PubMed PMID: 22473097.

5. Jacobs EJ, Thun MJ, Bain EB, Rodriguez C, Henley SJ, Calle EE. A large cohort study of long-term daily use of adult-strength aspirin and cancer incidence. Journal of the National Cancer Institute. 2007;99(8):608-15. doi: 10.1093/jnci/djk132. PubMed PMID: 17440162.

6. Zhao Q, Wang Z, Wang Z, Wu L, Zhang W. Aspirin may inhibit angiogenesis and induce autophagy by inhibiting mTOR signaling pathway in murine hepatocarcinoma and sarcoma models. Oncology letters. 2016;12(4):2804-10. doi: 10.3892/ol.2016.5017. PubMed PMID: 27698862; PubMed Central PMCID: PMC5038195.

7. Castoldi F, Pietrocola F, Maiuri MC, Kroemer G. Aspirin induces autophagy via inhibition of the acetyltransferase EP300. Oncotarget. 2018;9(37):24574-5. doi: 10.18632/oncotarget.25364. PubMed PMID: 29872488; PubMed Central PMCID: PMC5973857.

8. Wu Y, Wang Z, Kong J, Zhang J, Ling R. [Aspirin inhibits the proliferation of breast cancer cells via inducing apoptosis and autophagy]. Xi bao yu fen zi mian yi xue za zhi = Chinese journal of cellular and molecular immunology. 2017;33(10):1348-53. PubMed PMID: 29169419. 
9. Huang Z, Fang W, Liu W, Wang L, Liu B, Liu S, et al. Aspirin induces Beclin-1-dependent autophagy of human hepatocellular carcinoma cell. European journal of pharmacology. 2018;823:58-64. doi: 10.1016/j.ejphar.2018.01.031. PubMed PMID: 29408091.

10. Claudius AK, Kankipati CS, Kilari RS, Hassan S, Guest K, Russell ST, et al. Identification of aspirin analogues that repress NF-kappaB signalling and demonstrate anti-proliferative activity towards colorectal cancer in vitro and in vivo. Oncology reports. 2014;32(4):1670-80. doi: 10.3892/or.2014.3373. PubMed PMID: 25109257.

11. Zhang X, Feng H, Li Z, Guo J, Li M. Aspirin is Involved in the Cell Cycle Arrest, Apoptosis, Cell Migration, and Invasion of Oral Squamous Cell Carcinoma. International journal of molecular sciences. 2018;19(7). doi: 10.3390/ijms19072029. PubMed PMID: 30002310; PubMed Central PMCID: PMC6073368.

12. Ying J, Zhou HY, Liu P, You Q, Kuang F, Shen YN, et al. Aspirin inhibited the metastasis of colon cancer cells by inhibiting the expression of toll-like receptor 4. Cell \& bioscience. 2018;8:1. doi: 10.1186/s13578-017-0198-7. PubMed PMID: 29308184; PubMed Central PMCID: PMC5753438.

13. Ogawa $\mathrm{F}, \mathrm{Amano} \mathrm{H}$, Ito $\mathrm{Y}$, Matsui $\mathrm{Y}$, Hosono $\mathrm{K}$, Kitasato $\mathrm{H}$, et al. Aspirin reduces lung cancer metastasis to regional lymph nodes. Biomedicine \& pharmacotherapy $=$ Biomedecine $\&$ pharmacotherapie. 2014;68(1):79-86. doi: 10.1016/j.biopha.2013.11.006. PubMed PMID: 24331369.

14. Bibbins-Domingo K, Force USPST. Aspirin Use for the Primary Prevention of Cardiovascular Disease and Colorectal Cancer: U.S. Preventive Services Task Force Recommendation Statement. Annals of internal medicine. 2016;164(12):836-45. doi: 10.7326/M16-0577. PubMed PMID: 27064677.

15. Sperling CD, Verdoodt F, Aalborg GL, Dehlendorff C, Friis S, Kjaer SK. Low-dose aspirin use and endometrial cancer mortality-a Danish nationwide cohort study. Int J Epidemiol. 2019. Epub 2019/12/18. doi: 10.1093/ije/dyz253. PubMed PMID: 31845990.

16. Skriver C, Dehlendorff C, Borre M, Brasso K, Larsen SB, Tjonneland A, et al. Associations of low-dose aspirin or other NSAID use with prostate cancer risk in the Danish Diet, Cancer and Health Study. Cancer Causes Control. 2019. Epub 2019/12/12. doi: 10.1007/s10552-019-01252-5. PubMed PMID: 31823168.

17. Zhou J, Xia S, Li T, Liu R. Could aspirin be a lifesaver for prostate cancer patients in prostate cancerspecific mortality?: an update systematic review and meta-analysis. BMC Cancer. 2019;19(1):1186. Epub 2019/12/07. doi: 10.1186/s12885-019-6415-5. PubMed PMID: 31805980; PubMed Central PMCID: PMCPMC6894469.

18. Kim MH, Park SM, Yun YH, Hwang IC. Aspirin Does Not Prevent Pancreatic Cancer in a Large Asian Cohort. Cancer Epidemiol Biomarkers Prev. 2019;28(4):826-8. Epub 2019/01/16. doi: 10.1158/10559965.EPI-18-1325. PubMed PMID: 30642844.

19. Frisk G, Ekberg S, Lidbrink E, Eloranta S, Sund M, Fredriksson I, et al. No association between lowdose aspirin use and breast cancer outcomes overall: a Swedish population-based study. Breast Cancer Res. 2018;20(1):142. Epub 2018/11/22. doi: 10.1186/s13058-018-1065-0. PubMed PMID: 30458873; PubMed Central PMCID: PMCPMC6247765. 
20. Wang T, Parada H, McClain KM, Bradshaw PT, Terry MB, Teitelbaum SL, et al. Pre-diagnostic aspirin use and mortality after breast cancer. Cancer Causes Control. 2018;29(4-5):417-25. Epub 2018/03/09. doi: 10.1007/s10552-018-1020-5. PubMed PMID: 29516320.

21. Langley RE, Burdett S, Tierney JF, Cafferty F, Parmar MK, Venning G. Aspirin and cancer: has aspirin been overlooked as an adjuvant therapy? Br J Cancer. 2011;105(8):1107-13. Epub 2011/08/19. doi: 10.1038/bjc.2011.289. PubMed PMID: 21847126; PubMed Central PMCID: PMCPMC3208483.

22. Liu JF, Jamieson GG, Wu TC, Zhu GJ, Drew PA. A preliminary study on the postoperative survival of patients given aspirin after resection for squamous cell carcinoma of the esophagus or adenocarcinoma of the cardia. Ann Surg Oncol. 2009;16(5):1397-402. Epub 2009/02/26. doi: 10.1245/s10434-009-0382-z. PubMed PMID: 19241108.

23. Spence AD, Busby J, Johnston BT, Baron JA, Hughes CM, Coleman HG, et al. Low-Dose Aspirin Use Does Not Increase Survival in 2 Independent Population-Based Cohorts of Patients With Esophageal or Gastric Cancer. Gastroenterology. 2018;154(4):849-60 e1. Epub 2017/11/11. doi: 10.1053/j.gastro.2017.10.044. PubMed PMID: 29122547.

24. Araujo JL, Altorki NK, Sonett JR, Rodriguez A, Sungur-Stasik K, Spinelli CF, et al. Prediagnosis aspirin use and outcomes in a prospective cohort of esophageal cancer patients. Therap Adv Gastroenterol. 2016;9(6):806-14. Epub 2016/11/03. doi: 10.1177/1756283X16657985. PubMed PMID: 27803735; PubMed Central PMCID: PMCPMC5076766.

25. Rice TW, Blackstone EH, Rusch VW. 7th edition of the AJCC Cancer Staging Manual: esophagus and esophagogastric junction. Annals of surgical oncology. 2010;17(7):1721-4. doi: 10.1245/s10434010-1024-1. PubMed PMID: 20369299.

26. Usman MW, Luo F, Cheng H, Zhao JJ, Liu P. Chemopreventive effects of aspirin at a glance. Biochimica et biophysica acta. 2015;1855(2):254-63. doi: 10.1016/j.bbcan.2015.03.007. PubMed PMID: 25842298.

27. Li P, Wu H, Zhang H, Shi Y, Xu J, Ye Y, et al. Aspirin use after diagnosis but not prediagnosis improves established colorectal cancer survival: a meta-analysis. Gut. 2015;64(9):1419-25. doi: 10.1136/gutjnl-2014-308260. PubMed PMID: 25239119.

28. Henry WS, Laszewski T, Tsang T, Beca F, Beck AH, McAllister SS, et al. Aspirin Suppresses Growth in PI3K-Mutant Breast Cancer by Activating AMPK and Inhibiting mTORC1 Signaling. Cancer Res. 2017;77(3):790-801. doi: 10.1158/0008-5472.CAN-16-2400. PubMed PMID: 27940576; PubMed Central PMCID: PMCPMC5290090.

29. Kilari RS, Bashir AIJ, Devitt A, Perry CJ, Safrany ST, Nicholl ID. The Cytotoxicity and Synergistic Potential of Aspirin and Aspirin Analogues Towards Oesophageal and Colorectal Cancer. Curr Clin Pharmacol. 2019;14(2):141-51. doi: 10.2174/1574884713666181112141151. PubMed PMID: 30417794.

\section{Figures}


A

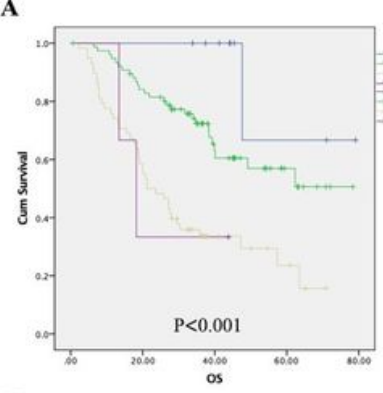

E

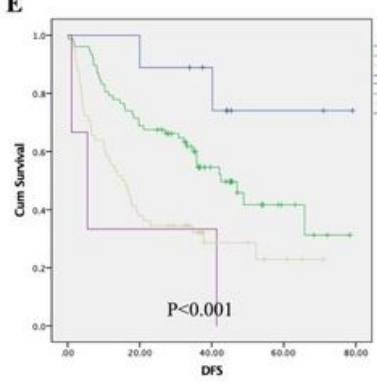

B
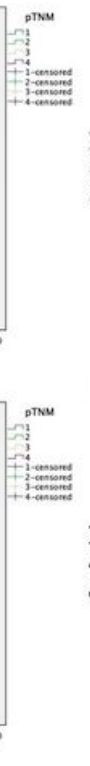

,
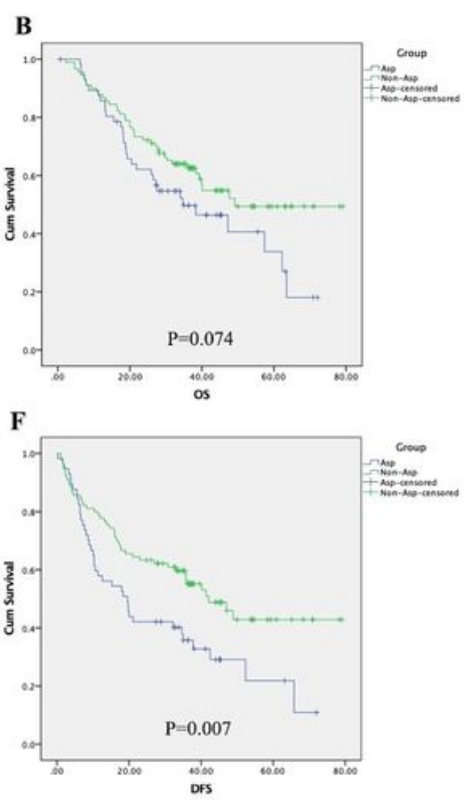

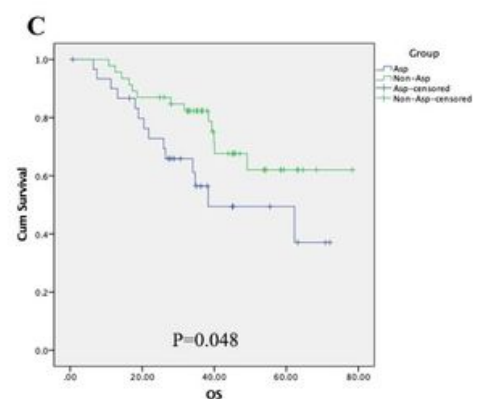

G
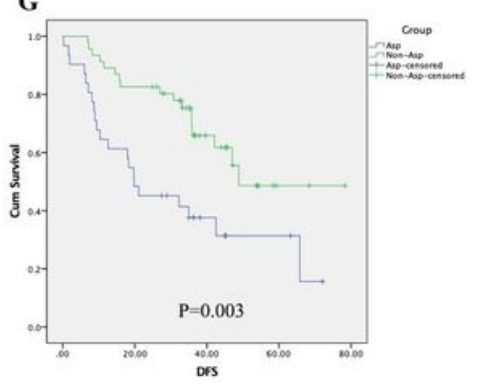

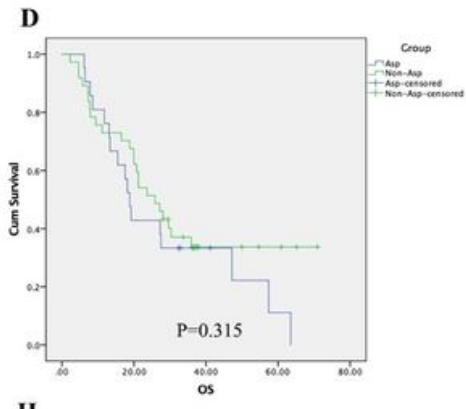

H

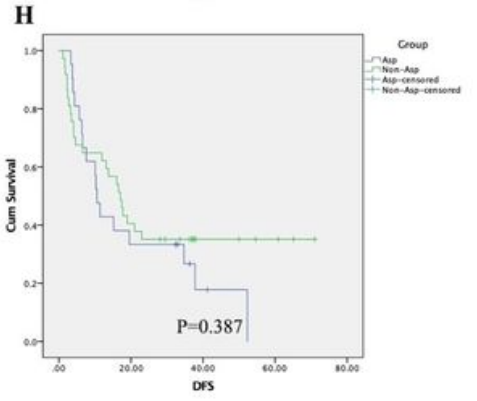

Figure 1

Kaplan-Meier survival curves of the differences of OS and DFS. (A) OS decreased significantly as pTNM stage increased; (B) OS decreased in aspirin group than in non-aspirin group although it was not significant; (C) In pTNM stage 2, OS of patients in aspirin group was worse than patients in non-aspirin group; (D) In pTNM stage 3, no significance was found between aspirin groups; (E) DFS decreased as pTNM stage increased however, it didnot reach the significance; (F) DFS decreased in aspirin group than in non-aspirin group; (G) In pTNM stage 2, DFS of patients in aspirin group was worse than patients in non-aspirin group; $(\mathrm{H})$ In pTNM stage 3, no significance was found between aspirin groups. 